\title{
Domain D: Networks
}

\begin{abstract}
In this chapter we examine how local organizations, affinity groups and the formal and informal networks they form provide the basis for the collective, coordinated actions needed for agroecological transformation at different scales. Civil society-driven networks are crucial because they facilitate a kind of cooperation that cannot be generated by the market or the state. On the other hand, the absence of appropriate networks can substantially limit agroecological transition, for example where political dynamics undermine or weaken the development of networks for collective action. Another disabling dimension of this domain is the compartmentalization of networks (e.g. by commodity group), which is a contradiction to the holism of agroecology. Perhaps most challenging is the growing individualization of society that is creating a growing barrier to cooperativism.
\end{abstract}

Keywords Local organizations • Social movements • Farmer organizations $\bullet$ Collective action

As we have seen, local groups and multi-actor networks rooted in civil society are pivotal for making agroecological transformations possible. The other key domains-knowledge, systems of exchange, discourse, efforts to address inequity - are all generated through social organization and networks acting at different scales. Local organizations, affinity groups and the formal and informal networks they form provide the basis for the

(C) The Author(s) 2021

C. R. Anderson et al., Agroecology Now!, https://doi.org/10.1007/978-3-030-61315-0_7 
collective, coordinated actions needed for agroecological transformation at different scales (Pimbert 2005, 2009).

While experimentation and innovation on farms are generally considered critical agroecological 'field laboratories', social organization in networks increase the reach, depth and potential of such innovations. In this sense, Mier y Terán Giménez Cacho et al. (2018) argue that organicidad, or the degree of organization, is the "culture medium" on which agroecology grows. This may explain why agroecological farmers tend to have closer engagement with networks (e.g. of fellow farmers, academics and NGOs) than conventional farmers (Teixeira et al. 2018). Indeed, there is widespread evidence on the importance of grassroots networks in developing social innovation and alternative approaches to the dominant regime in food, farming and beyond. Such networks are key for connecting 'islands of success', building systems of exchange that enable learning and the co-production of knowledge, share labour and resources, and work collectively in the political arena.

As we will detail here, while mainstream agriculture is advancing through processes of individualization and de-territorialization, collective organization in networks and organizations is supporting the transition to agroecology. Through that process, local alliances and movements are better able to adaptively manage agroecosystems and landscapes; coordinate human skills, knowledge and labour to generate economic wealth and exchanges in multifunctional food systems; and support shifts in governance of food systems as well as facilitate coordinated action for policy and institutional change.

\section{EnABLing Conditions}

Innovations in agroecology do not automatically spread to other socioenvironmental contexts. They depend on networks of people with the agency to do so. As such, networks enable innovative practices to mature, to reach a greater diversity and numbers of actors such as food consumers, to access resources and to link up to power-holders, which can create opportunities for influencing the regime. Frank Geels and Jasper Deuten (2006) argue that innovation networks generally emerge first with isolated experiments, later moving on to aggregate lessons learned from these through exchanges between actors such as policy-makers and scientists. This phase is crucial for stabilizing socio-technical niches for innovation such as agroecology. After that, intermediaries such as local authorities and 
relatively stable networks form, bringing together knowledge from local initiatives as well as new actors and activities.

Civil society engagement in these networks is critical because it facilitates a kind of cooperation that cannot be generated by the market or the state (van der Ploeg 2018). 'Endogenous' farmers' networks, for example, have helped increase agricultural diversity and build knowledge, skills and cooperation needed to improve nutrition among farmers (Deaconu et al. 2019). Indeed, self-organization in agroecology is an effective but neglected force for spreading practice, knowledge and participation. In this respect, Schot and Geels (2008) point out that to be effective, networks must be deep: members should also be able to generate commitment and resources within their own organizations and networks. Critical pedagogy, horizontal learning, transformative learning and intercultural dialogue are important in this respect because they build trust across boundaries, nurture a collective capacity for critically reflexive practice, address inequity and solve conflicts.

At the same time, and somewhat paradoxically, 'weak' network ties and fluid relationships allowing collaboration, as opposed to close bonds shared among like-minded people, can be important in generating and sustaining change (Nelson et al. 2013). The robustness of networks for agroecology depends on the material and social resources they are able to develop, wield and maintain and the way these are combined to mutually reinforce each other.

Within networks, certain capacities can develop: to organize, to learn and to continuously improve practice by distancing from extractive markets, upstream and downstream while collectively constructing markets for agroecologically produced goods (see Chap. 6 on the systems of economic exchange domain). Other such capacities include the ability to develop a shared sense of place and identity, the commitment to collaborate towards a common goal, and processes of critical education and peerto-peer knowledge building (Anderson et al. 2019; see also Chap. 5 on the knowledge and culture domain). The more numerous the connections between these resources, the more attractive, accessible and useful the networks become for agroecology transformations.

Experimentation by, within and between networks can also focus on institutional issues such as markets or governance. New formal or informal institutions for local regulation and governance are often created in networks to fill institutional voids, leading to salutary developments such as innovative public policies. When such policies prove workable, they can in 
turn expand the reach of such territorial governance and promote institutional collaboration between state and non-state actors. For example, Brazil's Ecoforte programme explicitly recognizes and financially supports the role of territorial networks and governance for the promotion of agroecology (González de Molina et al. 2019).

State support can be crucial for the development of new institutions such as common innovation platforms and learning networks. To ensure that local needs and ownership are prioritized, Yoko Kanemasu (2008) argues that such support to networks should be based on broad participation across sectors, bringing together agriculture, health, environment and other actors with a stake in food systems.

More generally, networks supporting agroecology are most likely to thrive in contexts where a vibrant civil society is encouraged and nurtured through policies, regulations, norms and institutions that support human rights and bottom-up processes. In Thailand, for example, sustainable agricultural groups such as the Alternative Agriculture Network, established in the 1980s by farmers and local NGOs, were afforded the political space they needed to develop when the government launched major programmes to support sustainable, organic and self-sufficient farming.

\section{Bringing on Board New Actors}

The most promising agroecology initiatives are those where grassroots actors reach across divides and organize to get others on board to create new, multi-actor constituencies with common aims and interests (IPESFood 2016). Involving outsiders in a process of social organization can increase the scope of resources available to them, such as knowledge, access to other networks, political influence and finance. In turn, these can increase the reach of agroecology.

A diversity of organizations and actors with different functions, powers, resources, membership and responsibilities is usually needed in a network to coordinate the variety of activities needed to amplify agroecology. Interlinked organizations provide the broad institutional landscape-and the means for coordinated action-required to manage the dynamic social and ecological complexities in which agroecology-based food systems are embedded, and for the systems themselves (Pimbert 2009).

For example, as described by Leonardo van den Berg et al. (2016), in the municipality of Araponga in the state of Minas Gerais, Brazil, networks that bring together farmer unions, academic groups and NGOs have been 
an important factor of success for both the development and territorial spread of agroecology and for acquiring financial support, fostering further experimentation and innovation, and obtaining formal legitimacy. This case emphasizes the importance of a step-by-step process for drawing in both new actors and new activities: first land reform, then agroecology. This strengthened and increased the efficacy of the network with every step, thereby deepening the transformational process.

Dynamic alliances for agroecology are also being built at the international scale, such as the Nyéléni network comprising La Via Campesina, the World March of Women and the Network of Peasant Organizations and Agricultural Producers in West Africa (ROPPA). In these, the movements of a diverse range of food producers, consumer constituencies and other actors engage in discussions, exchanges and joint activities to promote agroecology and food sovereignty (see www.foodsovereignty.org).

At a certain point in a network's development, it can be helpful to engage policy-makers, scientists and other institutional actors from within the dominant regime. State officials might join in, particularly those sympathetic to agroecology or who can contribute to its learning processes by applying or 'translating' the official literature and cognitive frameworks often used by state entities (Ortiz et al. 2017). In this way, insights, resources and knowledge from the regime can strategically modify the agroecological niche, while knowledge, discourse, governance and other elements of agroecology may inform and change the dynamics of the regime. Networks can therefore become important spaces for interaction between the agroecological niche and the regime.

However, the involvement of such actors in networks, such as through the injection of financial resources, can also become problematic by subtly leading to gradual co-optation (see Part III). Incentives and support can enable elements of agroecology that most resemble those of the status quo and diminish those that are transformative. A study of agroecology niches in South Africa (Metelerkamp et al. 2020) found that "state-led extension services and formal training institutions are of little help to niche pioneers and instead contribute toward the path-dependency of the current food regime".

So, while necessary, working within such networks is also complex and power-laden, posing a risk of depoliticization. Care must be taken regarding the influence of well-resourced and often well-meaning bureaucrats wholike NGOs, scientists, privileged activists and other power-holders-can wield disproportionate influence over the way agroecology scales out and 
up. Risks of co-optation emerge when the agendas and priorities of more powerful participants change the nature and values of niche innovations and the internal dynamics of networks. Agroecological farmers and others within the niche may end up marginalized. This happened, for instance, when organic agriculture was absorbed into corporate-led chains over the last few decades, undermining the values and transformative potential of the pioneering organic movement on which the practice was founded.

This is a conundrum in agroecology: the influence of the regime can fragment, diminish and even intentionally suppress the knowledge, markets, equity, discourse, access and rights over nature required for agroecology. Substantial resources are then needed to rebuild these domains.

The issue also points at the crucial role of facilitators and coordinators in strengthening local organizations and weaving together effective networks. New actors may find it difficult to embrace the same range of values, expectations, rules, norms and politics that have provided consistency in emergent agroecological initiatives and that underpin their transformative potential. The inclusion of such actors should be facilitated to avoid creating any dependencies on scientists and political parties, for instance, that undermine autonomous, long-term, genuine agroecological transformations (Ortiz et al. 2017).

As decisions are made over whom to admit to networks, the question of equity related to class, gender, caste, religious and race divisions comes to the fore. Agroecological organizations and networks are not always inclusive towards women and the marginalized nor-as we have notedare they free from manipulation by more powerful actors. They can be plagued by internal inequities and social injustices, with decisions taken by men, landowners, people in 'upper' castes or privileged classes at the expense of the relatively powerless-women, landless farm workers, pastoralists, forest peoples and urban slum dwellers among them. Attempts to build intersectoral and intersectional movements-for example between women's groups, food movements, climate activists and migrant networks - are a promising pathway to solving shortcomings related to equity, gender, social inclusion, race, privilege and entitlement. As Eric HoltGimenez and Yi Wang (2011) point out, the political direction of the food justice movement's organizational alliances will be towards either reform or transformation, depending on how issues of race and class are resolved. These issues are further elaborated in Chap. 8 on the equity domain.

Various forms of effective formal and informal multi-actor networks for agroecology include community-supported agriculture initiatives and 
collaborations between groups of agricultural producers and researchers. In Colombia, at territorial and national levels, networks including farmers' associations and families, supportive NGOs, donors, researchers and government entities successfully aggregated, shared and applied lessons and proved key in advancing agroecology and family farming (Ortiz et al. 2017). Food policy councils are an increasingly relevant approach at the municipal and sometimes territorial level, bringing together people from sectors such as food, public health, agribusiness, retail, policy and civil society to develop long-term food-related strategies. Multi-stakeholder platforms, although not without problems, are a critical figure for advancing land tenure governance around the world (Box 7.1).

\section{Box 7.1 Networking Lessons from a Multi-actor Platform for Land Tenure in South Africa}

In South Africa, an inclusive and participatory networking approach spurred the government to implement the Voluntary Guidelines on the Responsible Governance of Tenure of Land, Fisheries and Forests (VGGT) to address three national priorities: food security and nutrition, sustainable and equitable natural resource management, and sustainable land reform. At the heart of this collaborative process, which began in 2013, is a multi-stakeholder platform where dialogue and consensus-building on priorities could take place. National VGGT workshops and learning events and programmes built the awareness and capacity of different actors in civil society, grassroots organizations and beyond to use the VGGT effectively.

Several lessons can be drawn from this initiative. First, a process involving multiple actors strengthens the consensus around the needed policy and legal reforms: it can generate or increase the political will needed to adopt and implement such reforms. Second, this experience showed the importance of time: to progressively build trust among partners, even within a specific actor group; to reach a common understanding of the situation; and to develop a consensus on the common strategy. Third, it stressed the critical role of a credible, neutral convener and facilitator in the process, not least to address and overcome power asymmetries. Lastly, a core group of people around this facilitator is also needed to keep the momentum and move forward.

Source: HLPE (2018) 


\section{Disabling Conditions}

Today's food system is reinforced by a mesh of interrelated market and policy incentives for subsidies, retail, research, international trade and more, as well as social and cultural dynamics that lock farmers into agriculture that is specialized, large scale and highly dependent on external inputs (IPES-Food 2016). This approach can significantly constrain the development of effective networks for agroecological transformation.

While agroecology can be practised by one farmer, a transformative agroecology is deeply collaborative. Yet decades of neo-liberalization have created a worldview in which the individual is the defining unit of economic and political action. Individual choice and freedom in a free market has become culturally and institutionally entrenched. Farmers are seen as entrepreneurs and citizens as consumers, while the role of civil society is depoliticized and degraded.

Mainstream discourse on conservation and development envisages that the number of farmers, fishers and other people engaged in land- or waterbased livelihoods will shrink. Since the 1980s, 'get big or get out' has been a common credo. In this view, increased farm size is seen as a prerequisite for individual farmers eager to develop and become more included in the mainstream economy. Encouraging people who cannot (or will not) scale up to move out of agriculture and get jobs in the largely urban-based manufacturing and service sectors is seen as both desirable and necessary-regardless of the social and ecological costs. This dominant discourse on modernity and progress, and its focus on the individual farm, directly encourages and legitimates the active neglect and undermining of networks and social organization for agroecological transformation (this is further discussed in Chap. 9 on the discourse domain).

Another key barrier to developing effective multidisciplinary and multiactor networks for agroecology is the compartmentalization of different aspects of the food system. Institutions and organizations that focus on one specific aspect of the food system (such as technology, seeds, markets, natural resources, health and consumption) may lose sight of the holistic approach at the heart of agroecology. For example, within farmer organizations, a strong sectoral focus embedded in highly specialized production can also prevent networking between producers-a requirement for the spread of agroecology. Similarly, synergies are often lacking between governmental policy departments, for example those for agriculture, fisheries, forestry, education, health, water or the environment. This can create 
difficulties for an integrated approach to food systems. This 'pillarization' is also widespread in academic disciplines involved in research on agriculture, rural society or development. That the effect of this tendency is detrimental has long been pointed out by scholars, and has been discussed in detail in Chap. 5 (on the knowledge and culture domain).

Another major obstacle to the development of networks for agroecology has been the broad reluctance by state entities to empower such processes with the resources-budgetary, logistical, legal and political-to put their deliberations into practice. Official recognition has been critical for successful networks, especially in the early stages of transformation. When such resources are not allocated, involvement in networks can lead to exhaustion and disengagement. Perhaps most importantly, there is a need for much more recognition and support for food producers' organizations that enhance the agency, knowledge and identity of small-scale agricultural producers and their rights. This would steer policy and discourse away from their current emphasis on the economic vitality of farming, which dominates in mainstream farming organizations, research centres and policy institutions. The recent recognition of peasants' rights by the UN Human Rights Council may represent an important step forward in the global recognition of farmers' agency.

The development of agroecology networks can also be disabled by a country's political and societal context. In some countries, support for civil society may not exist; in China, the establishment of networks and local organizations with alternative views is discouraged and suppressed (Castella and Kibler 2015). In other countries, the political context can be outright hostile to dissenting social organization. Ellinor Isgren and Barry Ness (2017) describe how civil society organizations in Uganda historically have limited capacity or space for political organizing, fearing consequences such as deregistration, harassment or arrest. This is not unjustified: Uganda's recently passed NGO Act allows for tighter control of civil society. And in September 2017, Ugandan authorities closed down the bank accounts of the international NGO ActionAid, a strong advocate of agroecology and democratization in the country.

\section{REFERENCES}

Anderson, C. R., Maughan, C., \& Pimbert, M. P. (2019). Transformative Agroecology Learning in Europe: Building Consciousness, Skills and Collective Capacity for Food Sovereignty. Agriculture and Human Values, 36(3), 531-547. 
Castella, J.-C., \& Kibler, J.-F. (2015). Actors and Networks of Agroecology in the Greater Mekong Subregion. AFD.

Deaconu, A., Mercille, G., \& Batal, M. (2019). The Agroecological Farmer's Pathways from Agriculture to Nutrition: A Practice-Based Case from Ecuador's Highlands. Ecology of Food and Nutrition, 58(2), 142-165.

Geels, F., \& Deuten, J. J. (2006). Local and Global Dynamics in Technological Development: A Socio-Cognitive Perspective on Knowledge Flows and Lessons from Reinforced Concrete. Science and Public Policy, 33(4), 265-275.

González de Molina, M., Petersen, P. F., Peña, F. G., \& Capor, F. R. (2019). Political Agroecology: Advancing the Transition to Sustainable Food Systems. Boca Raton: CRC Press.

HLPE. (2018). Multi-stakeholder Partnerships to Finance and Improve Food Security and Nutrition in the Framework of the 2030 Agenda. Rome: HLPE.

Holt-Giménez, E., \& Wang, Y. (2011). Reform or Transformation? The Pivotal Role of Food Justice in the U.S. Food Movement. Race/Ethnicity: Multidisciplinary Global Contexts, 5(1), 83-102.

IPES-Food. (2016). From Uniformity to Diversity: A Paradigm Shift from Industrial Agriculture to Diversified Agroecological Systems. International Panel of Experts on Sustainable Food Systems (IPES).

Isgren, E., \& Ness, B. (2017). Agroecology to Promote Just Sustainability Transitions: Analysis of a Civil Society Network in the Rwenzori Region, Western Uganda. Sustainability, 9(8), 1357.

Kanemasu, Y. (2008). The Impact of Policy Arrangements. In J. D. v. d. Ploeg, \& T. Marsden (Eds.), Unfolding Webs-The Dynamics of Regional Rural Development (pp. 211-225). Koninklijke Van Gorcum.

Metelerkamp, L., Biggs, R., \& Drimie, S. (2020). Learning for Transitions: A Niche Perspective. Ecology and Society, 25(1), 14.

Mier y Terán Giménez Cacho, M., Giraldo, O. F., Aldasoro, M., Morales, H., Ferguson, B. G., Rosset, P., et al. (2018). Bringing Agroecology to Scale: Key Drivers and Emblematic Cases. Agroecology and Sustainable Food Systems, 42(6), 637-665.

Nelson, E., Knezevic, I., \& Landman, K. (2013). The Uneven Geographies of Community Food Initiatives in Southwestern Ontario. Local Environment, $18(5), 567-577$.

Ortiz, W., Vilsmaier, U., \& Acevedo Osorio, Á. (2017). The Diffusion of Sustainable Family Farming Practices in Colombia: An Emerging Sociotechnical Niche? Sustainability Science, 13(3), 829-847.

Pimbert, M.P. (2005). Supporting locally determined food systems: the role of local organizations in farming, environment and people's access to food. In: Bigg, T. and D. Satterthwaite (Eds) How to Make Poverty History. London: IIED. 
Pimbert, M. P. (2009). Towards Food Sovereignty. Reclaiming Autonomous Food Systems. Reclaiming Diversity and Citizenship Series. Coventry: Coventry University.

Schot, J., \& Geels, F. W. (2008). Strategic Niche Management and Sustainable Innovation Journeys: Theory, Findings, Research Agenda, and Policy. Technology Analysis os Strategic Management, 20(5), 537-554.

Teixeira, H., van den Berg, L., Cardoso, I., Vermue, A., Bianchi, F., Peña-Claros, M., et al. (2018). Understanding Farm Diversity to Promote Agroecological Transitions. Sustainability, 10(12), 4337.

van den Berg, L., Hebinck, P., \& Roep, D. (2016). 'We Go Back to the Land': Processes of Re-peasantisation in Araponga, Brazil. The Journal of Peasant Studies, 45(3), 653-675.

van der Ploeg, J. D. (2018). The New Peasantries: Rural Development in Times of Globalization: Earthscan Food and Agriculture.

Open Access This chapter is licensed under the terms of the Creative Commons Attribution 4.0 International License (http://creativecommons.org/licenses/ by $/ 4.0 /$ ), which permits use, sharing, adaptation, distribution and reproduction in any medium or format, as long as you give appropriate credit to the original author(s) and the source, provide a link to the Creative Commons licence and indicate if changes were made.

The images or other third party material in this chapter are included in the chapter's Creative Commons licence, unless indicated otherwise in a credit line to the material. If material is not included in the chapter's Creative Commons licence and your intended use is not permitted by statutory regulation or exceeds the permitted use, you will need to obtain permission directly from the copyright holder.

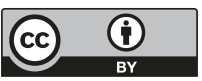

